\title{
Development and Theoretical Study of the Impact of the Working Body on the Soil
}

\author{
Marat Kalimullin ${ }^{1, *}$, Ramis Bagautdinov ${ }^{1}$, Radik Khamitov ${ }^{1}$, Rafkat Latypov ${ }^{2}$, Marat Salimzyanov ${ }^{3}$ and Rinat \\ Abdrakhmanov ${ }^{4}$ \\ ${ }^{1}$ Kazan State Agrarian University, Kazan, 420015, Russia \\ ${ }^{2}$ South Ural State Agrarian University, Chelyabinsk, 454080, Russia \\ ${ }^{3}$ Izhevsk State Agricultural Academy, Izhevsk, 426069, Russia \\ ${ }^{4}$ Tatar Institute of Personnel Development of Agrobusiness, Kazan, 420059, Russia
}

\begin{abstract}
The article discusses the features of the process of interaction of the blades of the teeth of the disk working body with the cultivated soil. If we take into account the fact that the parameters of the intensity of the impact exerted on the soil by the toothed working body will depend on the speed of movement, it will be possible to determine the values of the speed of an arbitrary point of the blade of the teeth. As a result of mathematical transformations and the application of the method of differentiation of the equation of their displacement, a formula was obtained for calculating the cutting speed for an arbitrary point of the blade of the teeth of a disk working body. Also, the acceleration of the points under consideration is determined and the dependences obtained as a result of theoretical studies are analyzed. The dependences demonstrate that the parameters of the impact speed and the trajectory of the blade movement directly depend on the shape of the cutting edge. They are also influenced by the angle of attack, the value of the inclination in relation to the vertical, as well as the speed of the planter movement. After analyzing the results obtained, it can be concluded that there is a noticeable decrease in the throwing of the upper soil layer to the side and the removal of the lower layer to the open surface of the field when exposed to a disk working body with teeth around the perimeter.
\end{abstract}

\section{Introduction}

The main agrotechnical requirements for planting potatoes are the uniform distribution of tubers over the sown area, in depth, laying them on a compacted bed and embedding with moist, loose soil. At the same time, fertilizers of standard or slightly increased moisture with continuous application should be evenly distributed over the surface of the field. The deviation in the seeding of fertilizers along the length of the path for disk devices should not exceed $25 \%$ of the average seeding, and in the working width $-15 \%$. Permissible deviation of fertilizer sowing by centrifugal spreaders across the working width is no more than $25 \%$.

A review of the existing classifications of the working elements of the opener group, in particular the openers for planting potatoes, showed that they are characterized by a wide variety of designs of the working bodies, which differ significantly both in principle of operation and in design. For a more reasonable choice of promising openers, it is necessary to systematize them according to the main criteria for performing the technological process and design features. In this case, in the general case, the openers for planting potatoes form three main groups: passive, rotary and combined [1-3].
When developing combined working bodies, it is necessary to strive not to replace individual operations, but to perform them together based on the use of new principles of influence on the cultivated soil, seeds and fertilizers in accordance with the agrotechnical requirements of a particular crop. At the same time, a new working body or progressive technology should create optimal conditions for the germination of planting material and the intensification of the initial phase of plant development, reliably provide them with moisture, heat, air and nutrients [4-7].

Many authors have studied the effect of rotary working bodies on the soil, in particular disc bodies. At the same time, they considered the shape, design parameters and main elements of the above working bodies [8-10].

It is known that the intensive interaction of the toothed rotary organs with the soil depends on a number of design and process parameters: the speed of their movement, which contributes to an increase in loosening (crumbling) of the soil and the destruction of weeds; the shape of the cutting edge and their elements, as well as the angles of attack and inclination to the vertical axis, significantly affecting the quality indicators of work [11-13].

\footnotetext{
Corresponding author: marat-kmn@yandex.ru
} 
Based on the above information, and taking into account the existing real need to find the most optimal parameters of the working bodies, the main task of this work is to ensure an increase in the efficiency of the process associated with planting potatoes. For this, it is necessary to improve the existing technologies and design of the working bodies of the device for planting potatoes. In addition, the proposed design changes and operating modes are substantiated.

\section{Materials and methods}

We have created a disc-type toothed working body, which is a structural component of the opener of a combined unit, which is used when planting potatoes. The working body is used for pre-planting soil cultivation (figure 1).

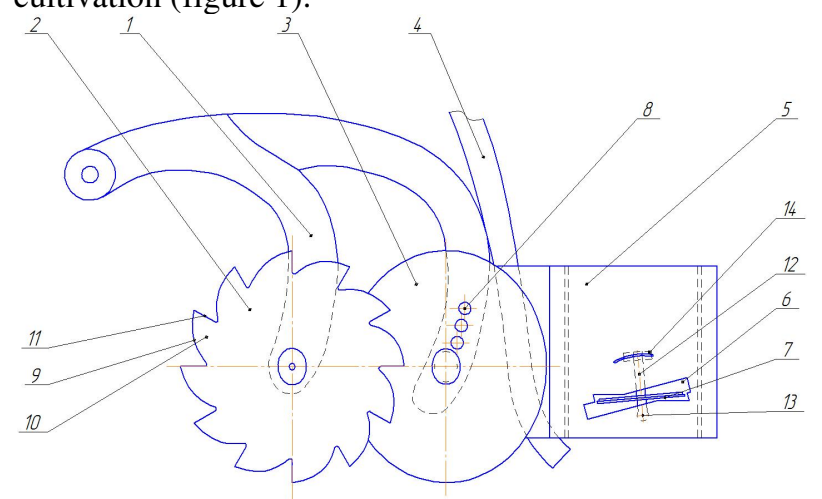

Fig. 1. Combined opener for planting potatoes.

Structurally, this opener is a rack 1 , on which a pair of toothed discs 2 are sequentially installed. The discs are installed at an angle of attack in the direction of travel and are inclined towards the vertical. The furrow former 3 is mounted in such a way as to have the possibility of its subsequent rearrangement in height. It is a pair of spherical discs.

The potato tuber guide 4 is located directly behind the furrow former, directly between the discs. The body of the passive type 5 has a rigid connection with the tuber guide 4 . It features a pair of sidewalls located at a certain distance from each other. A cutout window 6 is provided on the sidewalls, in which a rotating toothed disk of a flat shape 7 is located.

Such an implementation of the soil-transporting elements of the disc allows you to collect a certain portion of soil from the wall of the furrow formed by the furrow former, pass it through the cutout window and smoothly feed the cut portions of soil to cover the potato tubers. The lower end of the tuber guide 4 is smoothly bent in the direction opposite to the direction of movement of the opener.

Such a design of the working surface of the tuber guide 4 helps to reduce the rate of fall of the tubers during planting, which makes it possible to reduce injury to their sprouts while laying it on the bottom of the furrow. In addition, the spread of tubers along the width of the furrow is reduced, and soil clogging of the outlet of the tuber guide is excluded. All this contributes to the high-quality placement of tubers on the bottom of the furrow and their subsequent germination.

The furrow former 3 is mounted with the possibility of changing its position in height by resetting the axis of rotation of the spherical discs in the holes 8 made on the rack 1 of the furrow former 3 , each of which corresponds to a certain depth of furrow formation.

The front cutting edge 9 of each tooth 10 of flat discs 2 is made along a section of a logarithmic spiral and is placed with a radial bulge outward relative to the center of the discs, and the rear edge 11 of each tooth 10 is made in the form of a straight line that connects the sharp end (point) of the toe of the tooth with the center of the disc. In addition, each flat disc 7 is mounted on the vertical axis 12 by means of a bearing with the possibility of adjusting (changing) its angle of inclination relative to the vertical along a groove made in the sidewall.

The disc is equipped with trapezoidal teeth without sharpening, the lower part of the vertical axis being made in the form of a hinge 13, and the upper part by means of brackets 14 is fixed to the sidewall of the passive housing 5 from its inner side (closer to the longitudinal axis of the opener). The angle of inclination of the disc is changed by turning the vertical axis 12 on the hinge 13 relative to the vertical plane along the sector made above the groove and having a gradation of the angle of inclination, and fixing with a bolt. The gradation of the angles of inclination of the vertical axis 12 indicated in the sector was determined experimentally and is directly proportional to the mass of the supplied soil for sheltering potato tubers. By changing the angle of inclination of the discs, the thickness of the soil layer above the potato tubers when changing the depth of their planting, regulated by the furrow former, remains constant.

Such design features will provide an increase in the completeness of potato germination. This is due to the fact that the tubers will be laid in the loosened soil, after which they will be covered with a thin moist layer of soil.

Despite the versatility and functionality of the coulters, they alone cannot ensure the fulfillment of agricultural requirements when planting potatoes at a high level. Therefore, they must be used in tandem with a soil leveler, which is necessary both for leveling the surface of a potato field and for compacting the soil after planting to the required value.

The teeth themselves, located on the working body disk, will perform complex spatial movements. The blade of the teeth is made in the form of a section of a logarithmic spiral. Therefore, each point along its entire length will move at a different speed. Taking into account the information presented, consider the working body with a toothed disk shown in Figure 2. 


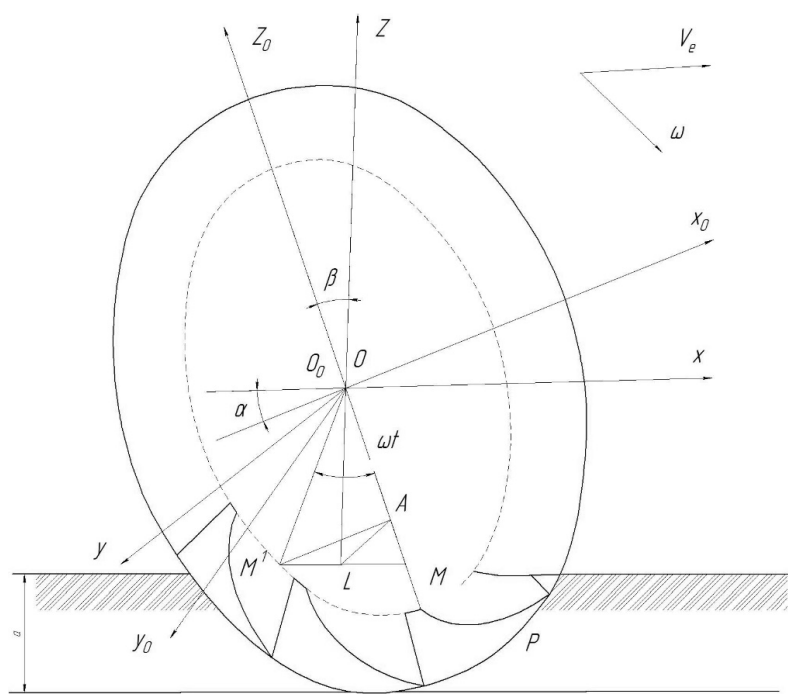

Fig. 2. Toothed disc working body in space.

\section{Results}

Based on the data of the analysis of many scientific works, it can be concluded that the blades of the teeth of the working bodies of the rotary type should be designed along a special curve in order to ensure the possibility of cutting off the soil layer with the effect of sliding and chipping. In addition, the blades should be able to deform the soil layer with minimal effort and eliminate the possibility of an increase in density at the bottom of the furrow. They should also minimize the waste of the cultivated soil $[9,14-16]$.

Taking into account the above and given in the studies of various scientists [14], the blades of the teeth of the working body should have the form of a logarithmic spiral. Such a spiral can be quite simply constructed using well-known techniques $[6,17]$.

When studying the features of the impact of a toothed blade on the soil layer, it is necessary to use an analytical expression that makes it possible to assess its arbitrary point $M$ in the process of spatial movement [18-19]. Moreover, as is known from theoretical mechanics, the resulting force of the point $\mathrm{M}$ is determined by the formula

$$
R_{M}=\sqrt{X^{2}+Y^{2}+Z^{2}} \text {. }
$$

Hence, the cutting speed of any point of the tooth blade $V_{p}$ is defined as

$$
V_{P}=\sqrt{\left(\frac{d X}{d t}\right)^{2}+\left(\frac{d Y}{d t}\right)^{2}+\left(\frac{d Z}{d t}\right)^{2}} .
$$

To determine the value $V_{p}$, we use the equations obtained by us for the points of the blade of the toothed disk working body in the following form

$$
\left.\begin{array}{l}
x=V_{e} t+\rho_{0} e^{f\left(\gamma_{i}+\frac{2 \pi}{z}\right)} \cdot\left[\sin \alpha \cdot \sin \beta \cdot \cos \left(\omega t-\gamma_{i}\right)-\cos \alpha \cdot \sin \left(\omega t-\gamma_{i}\right)\right] \\
y=\rho_{0} e^{f\left(\gamma_{i}+\frac{2 \pi}{z}\right)} \cdot\left[\sin \alpha \cdot \sin \left(\omega t-\gamma_{i}\right)+\cos \alpha \cdot \sin \beta \cdot \cos \left(\omega t-\gamma_{i}\right)\right] \\
z=-\rho_{0} e^{f\left(\gamma_{i}+\frac{2 \pi}{z}\right)} \cdot \cos \beta \cdot \cos \left(\omega t-\gamma_{i}\right)
\end{array}\right\}
$$

where $\gamma$ is current polar angle of radius vector, $\operatorname{rad} ; V_{e}$ is unit forward speed, $\mathrm{m} / \mathrm{s} ; t$ is time, sec; $\rho_{0}$ is initial radius vector, $\mathrm{mm} ; f$ is coefficient of friction; $e$ is base of natural logarithm; $\alpha$ is angle of attack, degree; $\beta$ is angle of inclination to the vertical axis, degrees.

Then, under the condition $V_{e}=$ const, after differentiating equations (3), we obtain

$$
\left.\begin{array}{l}
\frac{d x}{d t}=V_{e}-\rho_{i} \omega \cdot\left[\sin \alpha \cdot \sin \beta \cdot \sin \left(\omega t-\gamma_{i}\right)-\cos \alpha \cdot \cos \left(\omega t-\gamma_{i}\right)\right] \\
\frac{d y}{d t}=\rho_{i} \omega \cdot\left[\sin \alpha \cdot \cos \left(\omega t-\gamma_{i}\right)-\cos \alpha \cdot \sin \beta \cdot \sin \left(\omega t-\gamma_{i}\right)\right] \\
\frac{d z}{d t}=\rho_{i} \omega \cdot \cos \beta \cdot \sin \left(\omega t-\gamma_{i}\right)
\end{array}\right\} .
$$

Then, on the basis of formula (4), after transformations, we obtain an expression for determining the cutting speed of any point of the blade of a tooth of a disk working body

$$
V_{P}=\sqrt{V_{e}^{2}-\omega \rho_{0} e^{f\left(\gamma_{i}+\frac{2 \pi}{z}\right)} \cdot\left[2 V_{e} B+\omega \rho_{0} e^{f\left(\gamma_{i}+\frac{2 \pi}{z}\right)}\right]}
$$

where $B=\sin \alpha \cdot \sin \beta \cdot \sin \left(\omega t-\gamma_{i}\right)+\cos \alpha \cdot \cos \left(\omega t-\gamma_{i}\right)$.

Based on the foregoing, the total acceleration of the considered point $M$ is determined by the formula:

$$
W=\sqrt{W_{x}^{2}+W_{y}^{2}+W_{z}^{2}},
$$

where $W_{x}, W_{y}$ and $W_{z}$ is the acceleration of point $M$ along the coordinate axes:

$$
\left.\begin{array}{l}
W_{x}=-\rho_{i} \omega^{2} \cdot \sin \alpha \cdot \sin \beta \cdot \cos \left(\omega t-\gamma_{i}\right)+\rho_{i} \omega^{2} \cdot \cos \alpha \cdot \sin \left(\omega t-\gamma_{i}\right) \\
W_{y}=-\rho_{i} \omega^{2} \cdot \sin \alpha \cdot \sin \left(\omega t-\gamma_{i}\right)-\rho_{i} \omega^{2} \cdot \cos \alpha \cdot \sin \beta \cdot \cos \left(\omega t-\gamma_{i}\right) \\
W_{z}=\rho_{i} \omega^{2} \cdot \cos \beta \cdot \cos \left(\omega t-\gamma_{i}\right)
\end{array}\right\}
$$

After differentiating equation (5), you can get the tangential acceleration of the blade of the tooth of the disk working body:

$$
W_{\tau}=\frac{V_{e} \omega \rho_{i}}{V_{P}}\left[\cos \alpha \cdot \sin \left(\omega t-\gamma_{i}\right)-\sin \alpha \cdot \sin \beta \cdot \cos \left(\omega t-\gamma_{i}\right)\right] .
$$

In this case, the normal acceleration of an arbitrary point $M$ of the blade of a tooth of a disk working body is determined from the expression

$$
W_{n}=\sqrt{\frac{\omega^{4} \rho_{i}}{V_{P}^{2}}-V_{e}^{2} \omega^{2} \rho_{i}^{2} \cdot\left[\cos \alpha \cdot \sin \left(\omega t-\gamma_{i}\right)-\sin \alpha \cdot \sin \beta \cdot \cos \left(\omega t-\gamma_{i}\right)\right]^{2}}
$$

The dependences demonstrate that the parameters of the impact speed and the trajectory of the blade movement directly depend on the shape of the cutting edge. They are also influenced by the angle of attack, the value of the inclination in relation to the vertical, as well as the speed of the planter movement. These facts clearly confirm the graphs built on the basis of similar dependencies and shown in Figure 3 and 4. The graph $V_{p}=f\left(V_{e}\right)$ is constructed taking into account the passage of the entire length of the blade of the teeth in the soil through the vertical. At the same time $\omega t-\gamma_{i}=0$ and the 
ratio of the peripheral speed to the translational speed should be taken close to unity.

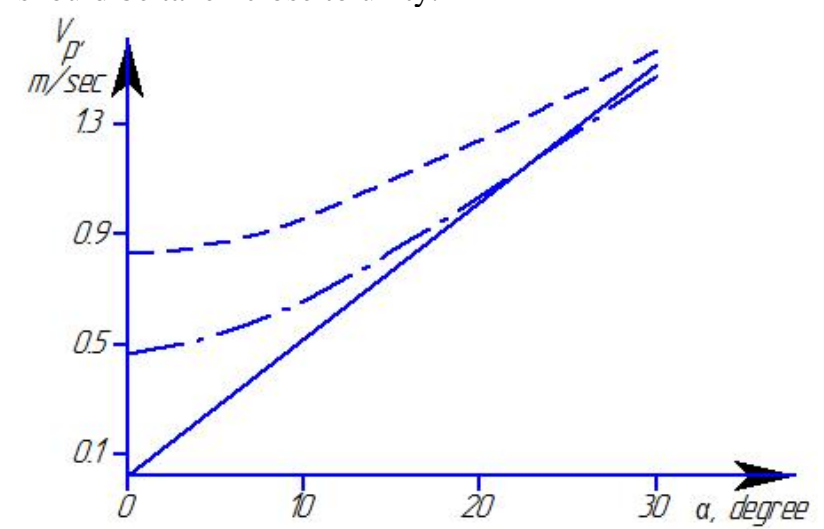

Fig. 3. Changing the cutting speed of a tooth blade of a disk working body depending on the angle of attack.

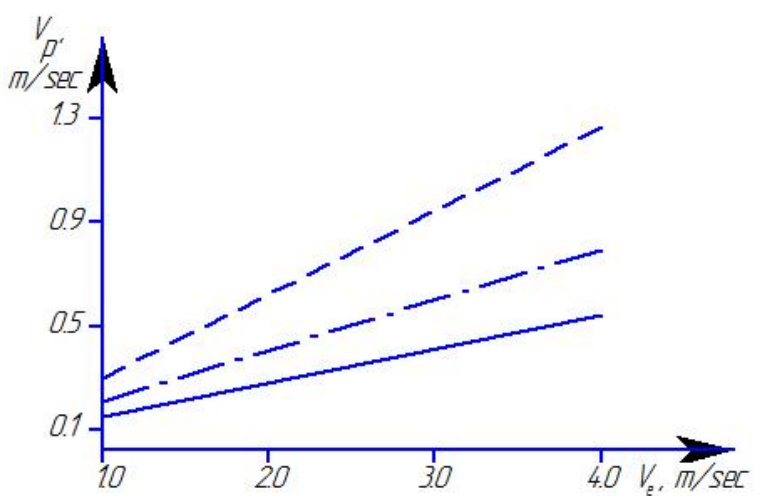

Fig. 4. Changing the cutting speed of a tooth blade of a disk working body depending on the speed of movement.

Based on the graph shown in Figure 3 and 4, we can say that the parameters of the cutting speed at the extreme and middle points of the blade will vary. Therefore, depending on the height of the tooth, the value of the soil throwback will change when the blade enters and exits the soil layer.

\section{Conclusion}

Thanks to the theoretical research carried out, it was possible to obtain a formula with which it is possible to determine the value of the cutting speed for any point belonging to the blade of the toothed working body. In addition, the accelerations of the points under consideration were determined and the analysis of the obtained dependencies was performed. In this regard, a reduction was found in the removal to the surface of the lower layer and the waste to the sides of the upper layer of the soil when using toothed disk working elements.

\section{Acknowledgements}

The study is supported by the grant of the President of the Russian Federation for young scientists-doctors of sciences MD-6281.2021.4.

\section{References}

1. V. Moskalevich, MOTROL, 11B, 179-189 (2009)

2. I. Ahmadi, Soil and Till. Res., 171, 1-8 (2017)

3. O.A. Fouda, J. Soil Sci. and Agric. Eng. Mansoura Univ., 7, 929-936 (2016)

4. K. Verbist, W.M. Cornelis, W. Schiettecatte, G. Oltenfreiter, M. Van Meirvenne, D. Gabriels, Engl. Soil Till., 96, 292-302 (2007)

5. P. Borowski, M. Klimkiewicz, M. Powałka, WEMA, Warsaw Univ. of Life Sci., 133 (2010)

6. A. Srivastava, E. Carroll, P. Roger, R. Dennis, American Society of Agricultural and Biological Engineers (2006), pp. 169-230

7. I. Mukhametshin, A. Valiev, F. Muhamadyarov, M. Kalimullin, F. Yarullin, Kinematic analysis of conical rotary subsoil loosener for tillage, 19th Int. Sci. Conf. Engineering For Rural Development Proceedings, Vol. 19 (20-22 May 2020) (Latvia Univ. of Life Sci. and Technol., Jelgava, 2020), pp. 1946-1952

8. V.P. Mazyarov, V.I. Medvedev, G.Z Gaifullin, L.P. Shershevsky, publ. Auth. St., no. SU 1373336 (1986)

9. Deep diggers give a high lift to yields, Farmers Weekly, 115, 42 (1991)

10. G. Sabourin, J. Richardeau, Patent FR, no. 9115937 (1993)

11. V.P. Mazyarov, V.I. Medvedev, The sub-cover ripper significantly reduces energy consumption during tillage (2013), Retrieved from: http://www.polytech21.ru/news/1846podpokrovnyj-rykhlitel-znachitelno-snizhaetenergozatraty-pri-pochvoobrabotke

12. A.P. Akimov, Yu.V. Konstantinov, Tract. and agricult. Mach., 12, 21-23 (2015)

13. S.A. Sidorov, V.K. Horoshenkov, D.A. Mironov, E.S. Luzhnova, Tract. and agricult. Mach., 8, 30-32 (2016)

14. A. Valiev, F. Muhamadyarov, 15th Int. Sci. Conf. Engineering for Rural Development Proc., Vol. 15 (Latvia Univ. of Agricult., 2016), pp. 1378-1385

15. M.N. Letoshnev, Agricultural machines. Agricultural equipment. Theory, calculation, design and testing (Moscow, 1955)

16. I.S. Mukhametshin, A.R. Valiev, A.V. Aleshkin, R.I. Ibyatov, Bull. of the Ulyanovsk State Agricult. Acad. 4, 50-182 (2018)

17. I.S. Mukhametshin, A.R. Valiev, P.I Makarov, Patent of RF, no. RU 2522320 (2013)

18. N.N. Nikitin, The course of theoretical mechanics (Higher School, Moscow, 1955)

19. M. Kalimullin, D. Ismagilov, R. Abdrakhmanov, M. Salimzyanov, R. Latypov, 19th Int. Sci. Conf. Engineering For Rural Development Proceedings, Vol. 19 (20-22 May 2020) (Latvia Univ. of Life Sci. and Technol., Jelgava, 2020) (2020), pp. 1224-1229 